\title{
Educação Ambiental: a mudança que faz a diferença
}

Caroline Maria Tavares de Sampaio ${ }^{1}$

\begin{abstract}
Resumo: Este estudo tem como objetivo evidenciar a importância da educação ambiental para a vida dos seres humanos. Primeiramente, foram feitas reflexões sobre a crise ecológica atual. Então, foram elencados vários problemas ambientais e muitas atitudes ecologicamente corretas que devem ser empregadas. Em seguida, os problemas ocasionados pela produção desenfreada de lixo foram analisados. Para que, assim, pudessem ser expostas as melhores maneiras de amenizar este fato. Por fim, foram feitas algumas considerações sobre a importância de se introduzir concretamente a educação ambiental na sala de aula. Então, a importância de cada profissional da educação foi assegurada. Pois, para que haja bons resultados nesse sentido, é imprescindível a cooperação diária de todos os membros da escola. Este trabalho foi executado com a pretensão de contribuir para que a educação ambiental consiga ser um divisor de águas na vida das pessoas, transformando projetos de vida em realidade. Esta preocupação com o meio ambiente é de suma importância para o mundo atual; pois, se não houverem drásticas mudanças na maneira de se relacionar com o meio, a vida dos seres humanos estará gravemente ameaçada.
\end{abstract}

Palavras Chave: Educação Ambiental; Problemas Ambientais; Atitudes Ecologicamente Corretas; Meio Ambiente.

\section{Environmental Education: the change that makes the difference}

Abstract: This paper aims to highlight the importance of environmental education for the life of human beings. First, reflections were made on the current ecological crisis. So were listed various environmental problems and many environmentally friendly attitudes that should be employed. Then the problems caused by rampant waste production were analyzed. For thus could be exposed the best ways to mitigate this fact. Finally, we made some considerations about the importance of introducing specifically environmental education in the classroom. So, the importance of each professional education was assured. For that there are good results in this direction, the daily cooperation of all members of the school is essential. This work was carried out with the intention of contributing to the environmental education can be a turning point in people's lives, making life projects into reality. This concern for the environment is of paramount importance for the world today; because, if there are no drastic changes in the way of relating to environment, the lives of human beings will be seriously threatened.

Keywords: Environmental Education; Environmental problems; Ecologically Correct attitudes; Environment.

\section{Introdução}

Este trabalho aborda a educação ambiental a partir de vários aspectos. Porém, deter-seá principalmente nas possíveis soluções para os problemas ocasionados pela grande produção de lixo. Além de tratar sobre a importância de se incluir de forma eficaz e dinâmica a educação ambiental na sala de aula.

\footnotetext{
1 Mestranda em Educação pela Anne Sullivan University. Licenciada em Letras, mestranda em Educação e pós-graduada em Linguística (FAFIRE-Recife), lecionando Língua Portuguesa. E-mail: carolsampaio80@gmail.com.
} 
Id on Line Revista Multidisciplinar e de Psicologia

Id on Line Multidisciplinary and Psycology Journal

Esta pesquisa se faz necessária para que todas as pessoas possam, o mais rapidamente possível, entender que agir de forma sustentável nas diversas situações do dia a dia é imprescindível para que a vida seja preservada no planeta. Muita coisa precisa ser mudada no comportamento das pessoas, para que a vida possa continuar acontecendo.

Esta obra será feita através de pesquisas bibliográficas, na qual os pontos de vista de alguns autores, sobre o tema em questão, serão expostos e analisados. Então, será estabelecida uma discussão com comentários e sugestões a respeito do assunto.

O objetivo almejado foi, justamente, tentar esclarecer sobre os perigos que a humanidade está correndo, se continuar agindo de forma imprudente no contato com os recursos naturais. Para que, a partir daí, possam ser mostradas as maneiras ecologicamente corretas de se relacionar com o meio. Pois, apesar deste assunto já ser bem explorado e discutido, na prática ainda está longe de ser executado com sucesso.

Primeiramente, serão feitas algumas reflexões sobre a crise ecológica atual. Daí então, será exposta uma relação sobre os principais problemas ambientais, seguida das possíveis soluções para se reverter ou, pelo menos, amenizar o caso.

Logo em seguida, alguns conceitos relacionados ao lixo serão esclarecidos. Depois, cada problema causado pelo grande acúmulo de resíduos será analisado. Para que, só então, sejam descritas e explicadas todas as maneiras adequadas de se tratar o lixo.

Por fim, será ressaltada a importância da inserção da educação ambiental na rotina da escola. A partir daí, serão lembradas as mudanças de comportamento e de pensamento que devem se impor com urgência no ambiente escolar. Pois, para que os resultados apareçam se faz necessária uma modificação geral no pensar e no agir de todos os integrantes das instituições educacionais.

\section{Problemas Ambientais}

Sabe-se que, devido ao desenvolvimento humano, é praticamente impossível alguém viver sem nunca poluir, nem agredir o meio ambiente. Porém, é essencial que cada pessoa procure agir de forma a prejudicar o mínimo possível a natureza. Visto que, a vida humana depende completamente de determinadas condições dos recursos naturais. 
Id on Line Revista Multidisciplinar e de Psicologia

Id on Line Multidisciplinary and Psycology Journal

Essa preocupação com os elementos da natureza surgiu já há um bom tempo, e, devido à tamanha degradação em que o meio ambiente já se encontra, é cada vez mais gritante a necessidade de mudança na maneira de pensar e agir. Uma mudança real na maneira de interagir com o meio ambiente é imprescindível, já que, apesar de teoricamente o assunto já ser bem explorado, na prática não existe ainda uma grande mobilização. A este respeito, pode-se afirmar que:

\begin{abstract}
A Educação Ambiental é parte do movimento ecológico. Surge da preocupação da sociedade com o futuro da vida e com a qualidade da existência das presentes e futuras gerações. Nesse sentido, podemos dizer que a EA é herdeira direta do debate ecológico e está entre as alternativas que visam construir novas maneiras de os grupos sociais se relacionarem com o meio ambiente. (CARVALHO, 2012, p. 51)
\end{abstract}

O movimento ecológico, tão vigente nos dias atuais, está diretamente ligado à preocupação com as futuras gerações. Deste modo, a educação ambiental vem como uma alternativa obrigatória para a consolidação de atitudes ecologicamente corretas na sociedade.

Como consequência da industrialização, os recursos naturais estão sendo cada vez mais transformados em bens de consumo. Se esta sede incansável de consumo não for contida com veemência, em breve o planeta estará desabitado. Urge a necessidade de mudança! E a única maneira de se reverter a situação atual é fazer com que se reduzam as demandas supérfluas. Para isso, é preciso que se promova uma mudança estrutural de comportamento, no qual sejam revalorizados a simplicidade, o conforto essencial, a frugalidade.

É importante lembrar que o ser humano é o único componente da natureza que a maltrata. $\mathrm{O}$ planeta Terra estaria em condições muito melhores se o homem não existisse. $\mathrm{O}$ homem faz muito mal ao planeta. Mas, na verdade, este mal que as pessoas causam ao seu habitat natural, se não for detido urgentemente, trará como consequências a extinção do próprio homem.

Quando fala-se que o ser humano destruirá o planeta Terra, não se quer dizer que tal astro será completamente exterminado, mas que as condições para que possa haver vida humana no planeta serão extintas. O homem não tem capacidade para destruir o planeta. Pois, mesmo que as agressões humanas ao meio ambiente cheguem a exterminar a raça humana da face da Terra, o planeta, certamente, recompor-se-á com o tempo. O que pode acontecer com tantas atitudes impensadas do ser humano, é, unicamente, a sua própria destruição. 
Os assuntos relacionados aos problemas ambientais são vários. Existe o problema do efeito estufa, do aquecimento global, das queimadas, da grande produção de lixo, do aterramento de entulhos, do desmatamento, das chuvas ácidas. Estes e tantos outros problemas devem ser repensados urgentemente para que possam surgir possíveis e coerentes soluções. E desta forma, as ações em prol da vida poderão ser intensificadas e reexploradas.

O consumismo desenfreado, que está ficando cada vez mais impregnado na vida das pessoas, é outro grande causador de prejuízos ambientais. Esta compulsão pelo consumo, que está sendo encarada como normal por causa do grande número de adeptos, faz com que seja cada vez maior a quantidade de lixo produzida. Os recursos naturais estão sendo cada vez mais degradados para serem utilizados como matéria prima na confecção de produtos.

Muitos estabelecimentos pregam ser ecologicamente sustentáveis. Pintam o local de verde, instalam lixeiras seletivas, entre outras atitudes. Mas, infelizmente, em muitos casos, essa preocupação ambiental não passa de marketing, ou seja, estratégia para atrair consumidores. Desta forma, o meio ambiente continua sofrendo as consequências.

A educação ambiental é imprescindível para que a vida humana possa continuar existindo. O homem não tem escolha, ou ele busca uma sensibilização urgente da sociedade, com relação à grande importância do meio ambiente, ou a vida humana será exterminada para sempre.

Dentre os diversos aspectos ligados à preservação do meio ambiente, podemos citar a coleta seletiva; a destinação adequada dos resíduos sólidos; a reciclagem; o desenvolvimento sustentável; a concreta inserção da educação ambiental no currículo escolar; o investimento maciço no transporte público urbano, ao invés do favorecimento do transporte individual; o racionamento do uso dos recursos naturais; entre outros.

As inúmeras ideias referentes à adequada utilização do meio ambiente podem e devem ser postas em prática em todos os momentos possíveis. Uma vez que elas são apenas o ponto de partida do caminho pelo qual o ser humano deve seguir com constância e precisão para que a sua vida continue a existir aqui na Terra.

Diante dos índices alarmantes de destruição ambiental em que se vive atualmente, o ser humano deve arregaçar as mangas e contribuir de todas as formas possíveis para que a situação possa ser revertida. Porém, para que a população acorde de verdade e sinta o real perigo que a vida humana está correndo, é imperativo que sejam feitos movimentos de conscientização, que 
levem as pessoas a repensarem as suas atitudes. E, desta forma, compreendam os diversos papéis que devem assumir diariamente para que os recursos naturais sejam preservados ao máximo.

É imprescindível que as pessoas se conscientizem de que os recursos naturais são a verdadeira fonte da vida. Portanto, defendê-los deve ser algo obrigatório. Já que proteger a natureza é defender a própria existência.

\title{
Soluções para o Lixo
}

Um dos grandes problemas da atualidade é a grande quantidade de lixo produzida diariamente. O lixo produzido pelas cidades, que é chamado de resíduo sólido urbano, reflete o nível de educação e cidadania do povo. A partir da análise dos tipos de resíduos ou entulhos encontrados em determinada região é possível se entender muito sobre a cultura do lugar. Ainda é possível acrescentar que:

\begin{abstract}
A questão do lixo gerado nas cidades é, sem dúvida, um dos grandes problemas na maioria dos municípios brasileiros. Os altos custos de implantação e manutenção dos sistemas de coleta e tratamento de lixo têm levado ao fracasso muitas tentativas de equacionamento. Como sempre, é a comunidade que vai sofrer os maiores impactos ambientais, produzidos pela falta de saneamento dos resíduos domésticos, hospitalares e industriais, com o aumento de doenças.

Pereira-Neto (1989) afirma que o equacionamento do lixo urbano no nosso país, na maioria dos casos, restringe-se apenas à coleta, seguida da destinação final a céu aberto "gerando as lixeiras, lixões ou monturos de lixo, que constituem-se no hábitat propício de vetores biológicos (moscas, mosquitos, baratas, roedores etc.) responsáveis pela transmissão de doenças infecciosas, como febre tifoide, salmonelos, amebíase, malária, dengue, cólera, leptospirose etc., além de contribuir sobremaneira com a poluição do solo, do ar e das águas". (apud cit in DIAS, 2004, p. 287)
\end{abstract}

O que se chama de resíduo sólido urbano é todo e qualquer tipo de resíduo produzido e descartado pela atividade humana de origem doméstica, comercial, agrícola, hospitalar, industrial e de varrição. Tais entulhos mostram muita coisa sobre as pessoas que os produziram. Eles são um indício de como elas tratam os recursos naturais.

Cada tipo de lixo tem uma origem e, portanto, não deve ser acumulado de forma aleatória. Tudo que for jogado fora deve ser separado para ter a destinação adequada. Os seres humanos não podem permitir que o lixo seja tratado de forma imprudente. Pois, desta forma, 
Id on Line Revista Multidisciplinar e de Psicologia

Id on Line Multidisciplinary and Psycology Journal

ele provocará inúmeros danos ao meio ambiente e, consequentemente, à própria vida no planeta Terra.

O acúmulo indevido de lixo é uma agressão enorme à natureza. Dentre as consequências possíveis, existe a poluição do solo, das águas e do ar. Além destas sequelas, o lixo tratado de forma irresponsável produz gases causadores do efeito estufa, causa maus odores, entupimento das redes de drenagem, entre outras coisas. Um exemplo bem simples da contaminação do solo e das águas, por causa do amontoamento do lixo de forma imprudente, é através do chorume, líquido escuro e de odor desagradável, que é produzido a partir da decomposição da matéria orgânica presente no lixo.

Outro impacto ambiental produzido pelo lixo é o assoreamento, processo observado no leito dos rios, como consequência do acúmulo de detritos. Pois este lixo que vai para o fundo dos rios interfere na quantidade de água que o rio comporta. Já que o lugar ocupado por entulhos, seria ocupado por água. E assim, em épocas de grande quantidade de chuvas e tornados, acontecem alagamentos, por causa do transbordamento das águas dos rios e lagoas.

O lixo em ambientes inadequados e tratado de forma irresponsável pode também contribuir para o aparecimento de vetores e transmissores de doenças. Isto acontece porque muitos animais, como o rato, a barata, o escorpião, a mosca e a formiga, são atraídos pelo lixo e nele se contaminam. Desta forma, o contato que tais animais infectados estabelecerem com o homem poderá lhe ocasionar graves problemas de saúde.

Para que seja possível minimizar os problemas relacionados com o lixo, primeiramente, é preciso que as pessoas repensem os seus hábitos de consumo. Para que, assim, possam praticar o consumo consciente, desvinculado das pressões da mídia. Se todos os seres humanos refletirem sobre o assunto, certamente diminuirá o consumo dos bens supérfluos e o desperdício será reduzido. Do mesmo modo, as pessoas poderão escolher consumir os produtos com vida útil mais longa.

As embalagens, que evoluíram bastante ao longo da história, hoje em dia, são responsáveis por uma grande parte dos resíduos sólidos. O consumo consciente, seguramente, trará como benefício a utilização de menos delas. E além disso, fará com que estes invólucros sejam mais reutilizados, isto é, os mesmos estarão sendo utilizados de novas formas, com novas finalidades. 
Outra prática indispensável para a redução dos prejuízos ambientais causados pelo lixo é a coleta seletiva. Cada tipo de lixo deve ter um destino diferente, de acordo com a sua procedência. Por isso que é tão importante que cada pessoa organize o seu lixo, separando o papel, o plástico, o vidro, o metal, o orgânico e a madeira. Isto facilitará bastante o trabalho do coletor de lixo. Porém, se as empresas que trabalham com o lixo não derem a devida destinação para cada categoria, o trabalho que cada pessoa teve, separando o seu lixo, terá sido em vão. Em melhores palavras, ainda pode-se dizer que:

\begin{abstract}
A população está sendo estimulada a utilizar recipientes separados para lixos diferentes. As sacolas azuis, contendo resíduos (lixo) inorgânicos seco, como plásticos (copos, sacos, embalagens), papel limpo (papelão, revistas, jornais), metais (latas, pilhas, tampas de garrafa, embalagens de alumínio) e vidros (garrafas, copos, cacos), são depositadas nos tonéis azuis. As sacolas amarelas, contendo resíduos orgânicos (restos de comidas, frutas, guardanapos, lenços de papel e fraldas descartáveis usadas), são depositadas nos tonéis amarelos. A coleta seletiva e a reciclagem já são realidades, em muitas cidades brasileiras. (DIAS, 2004, p. 289)
\end{abstract}

Tomando como base o que foi dito acima, fica óbvio a grande utilidade da separação do lixo em categorias. Pois, deste modo, tais resíduos, facilmente, poderão ser tratados de maneira adequada, numa etapa posterior. Porém, as consequências positivas do tratamento apropriado dado ao lixo só poderão ser, de fato, percebidas quando todas as pessoas estiverem conscientes e fazendo a parte delas.

Para um eficiente gerenciamento do lixo, é imperativo que ele seja embalado de maneira adequada para ser transportado ou disposto no solo. Com este propósito, deve-se sempre ter o cuidado de fechar o saco de lixo, tampar o recipiente que o contém, embalar os cacos de vidro e não deixar acumular os resíduos.

Nunca se pode esquecer de separar o lixo perigoso do lixo não-perigoso. Este é outro detalhe de suma importância no tratamento do lixo. Uma vez que uma pequena porção de lixo perigoso faz com que todo o lixo que estiver junto dele torne-se também perigoso. Um resíduo é perigoso quando pode apresentar riscos à saúde pública ou riscos ao meio ambiente. Em outras palavras, pode-se afirmar que um resíduo é perigoso quando ele for reativo, tóxico, corrosivo, patogênico e/ou inflamável. Possuindo pelo menos uma destas características, o resíduo é perigoso e deve ser separado do restante do lixo.

Ainda é importante lembrar que existe outra forma mais simples de se separar o lixo. Neste caso, o lixo pode ser classificado como seco, molhado ou resíduos especiais. O lixo seco 
Id on Line Revista Multidisciplinar e de Psicologia

Id on Line Multidisciplinary and Psycology Journal

é o inorgânico, o molhado é o orgânico e os resíduos especiais correspondem ao lixo perigoso. Sobre este fato, pode-se acrescentar:

Quando a prefeitura não puder praticar a coleta seletiva, o lixo pode ser coletado considerando a sua classificação em seco, molhado e resíduos especiais. O lixo seco é o resíduo inorgânico, que pode ou não ser reciclável. O lixo molhado é, basicamente, o resíduo orgânico. (MAZZINI, 2008, p. 27-28)

Quando o lixo é depositado em locais inadequados, ele pode ocasionar incêndios e problemas respiratórios. Portando, é imprescindível que as pessoas respeitem os horários de coleta, dispondo o lixo de forma segura e fácil de ser identificado de acordo com os seus procedentes.

Se cada tipo de lixo deve ter um rumo específico, serão elencadas agora todas as formas de disposição adequada que os resíduos sólidos podem ter. Para aqueles tipos de lixo que não são perigosos um dos destinos prováveis é a reciclagem. A reciclagem é o ato de transformar os resíduos através de um processo industrial, produzindo novos bens. Entre outros aspectos, a reciclagem propicia a economia de matérias-primas e de energia.

Uma atitude importante no combate aos estragos que o lixo pode ocasionar é a instalação de novas indústrias recicladoras. Estas fábricas, além de contribuírem para a redução do lixo, serão fonte de novos empregos diretos e indiretos. Desta forma, elas estarão gerando renda e melhorando o nível de vida dos catadores. No entanto, nem todo lixo que não é perigoso pode ser reciclado. Para estes casos, existe a reutilização, o aterramento, a compostagem e a incineração. A reutilização significa utilizar de novo os resíduos, para a sua função de origem, ou de outras formas, sem submetê-los a outro processo industrial.

Outro tipo de tratamento adequado para o lixo é o aterro sanitário, que é utilizado com o objetivo de prevenir a poluição e os danos à saúde. Neste caso, o lixo é compactado e organizado no solo em camadas, que são cobertas diariamente com terra. Este tipo de tratamento é feito, normalmente, em grandes áreas distantes dos centros urbanos. A drenagem do gás, das águas superficiais e do chorume, para posterior tratamento, é muito importante neste método. É bom lembrar ainda que este tratamento pode receber quantidades e tipos variáveis de lixo.

Outra alternativa para o lixo é a compostagem. Este tipo de tratamento só é possível com resíduos orgânicos. Pois, ele é um processo biológico de tratamento do lixo que consiste na decomposição dos restos de origem vegetal e animal, resultando em um produto final, o composto orgânico. Só podem ser utilizados neste método, os resíduos orgânicos isentos de 
Id on Line Revista Multidisciplinar e de Psicologia

Id on Line Multidisciplinary and Psycology Journal

contaminação por elementos tóxicos. O composto orgânico, que é produzido na compostagem, é utilizado como adubo.

Por fim, existe o método da incineração. Neste método, os resíduos sólidos são queimados em fornos e usinas próprias. Esta forma de tratar o lixo possui a vantagem de diminuir muito o volume de resíduos. Além disto, este método destrói os vírus e bactérias presentes em lixos patogênicos.

\title{
Como introduzir a Educação Ambiental na sala de aula
}

Quando se fala em educação ambiental, pretende-se fazer com que as pessoas ajam sempre conscientes da importância de preservar os elementos naturais. Nunca desperdiçar, não poluir, não agredir, enfim, adquirir uma postura constante de respeito ao meio ambiente. Esta é a finalidade principal da educação ambiental. No entanto, as diferenças que existem entre as atitudes ecologicamente corretas almejadas e as reais atitudes observadas são enormes. De acordo com o que foi dito, é possível acrescentar que:

\begin{abstract}
A dissonância entre os comportamentos observados e as atitudes que se pretendem formar é um dos maiores desafios da educação de um modo geral e da EA em particular. Muitas vezes, as atividades de EA ensinam o que fazer e como fazer certo, transmitindo uma série de procedimentos ambientalmente corretos. Mas isso nem sempre garante a formação de uma atitude ecológica, isto é, de um sistema de valores sobre como relacionar-se com o ambiente, sistema que será internalizado como uma visão de mundo orientadora dos posicionamentos do sujeito na escola e em outros espaços e circunstâncias de sua vida. (CARVALHO, 2012, p. 182)
\end{abstract}

Assim, pode-se declarar que a educação ambiental deve ser inserida concretamente e com urgência no contexto escolar. Para que, então, as atitudes ecologicamente corretas possam ser mais facilmente absorvidas pela população. É imprescindível que os docentes procurem incutir nos alunos um sistema interno de valores que lhes impulsione a agir sempre respeitando o meio ambiente. Referente ao exposto acima, é conveniente adicionar:

\footnotetext{
Uma pessoa ou grupo pode aprender a valorizar um ambiente saudável e não poluído e ter comportamentos como o de não sujar as ruas e participar dos mutirões de limpeza de seu bairro. Essa mesma pessoa ou grupo, no entanto, pode considerar adequada a política de produção e transferência de lixo tóxico para outra região e não se importar com a contaminação de um lugar distante de seu entorno imediato. Em uma perspectiva individualista, a preservação do seu meio ambiente local pode acontecer a despeito do prejuízo que outros possam vir a ter - por exemplo, outras populações que possam ser afetadas pelos resíduos tóxicos, pela falta de água potável etc. Assim,
} 
é possível adquirir comportamentos pontuais ambientalmente "corretos" sem recuar do compromisso com um pacto solidário e ecológico global, ou seja, é exibir comportamentos ambientalmente orientados sem desenvolver uma atitude ecológica no sentido pleno. (CARVALHO, 2012, p. 186)

Não adianta uma pessoa ter um comportamento favorável à vida, cuidando dos recursos naturais, em determinados lugares ou situações, se em outros locais e circunstâncias este mesmo indivíduo agredir o meio ambiente sem nenhum remorso. O que está em jogo é a vida humana no planeta Terra. É imprescindível que todos assumam comportamentos ecologicamente positivos num sentido global. Portanto, os docentes devem buscar, com urgência, maneiras eficazes de incutir nos estudantes a consciência verdadeiramente ecológica.

No entanto, grande parte dos docentes nunca teve um conhecimento aprofundado sobre a importância da Educação Ambiental. Eles precisam encontrar meios de chamar a atenção dos alunos para a urgente necessidade de preservar o meio ambiente, assumindo continuamente atitudes de respeito para com todos os recursos naturais. Sobre este assunto, é válido lembrar:

É prudente levarmos em conta que muitos professores nunca tiveram oportunidade de
estudar os referenciais teóricos da EA, não conhecem sua história, seus objetivos e
princípios. Portanto, grande parte das propostas de EA desenvolvidas é motivada pela
iniciativa dos docentes, não decorrendo de políticas públicas. E esses docentes,
mesmo não tendo acesso às inúmeras reflexões produzidas na área, "colocam a mão
na massa" e produzem conhecimentos de natureza empírica. (LEME, in
GUIMARÃES (org.), 2012, p. 88)

Apesar da falta de conhecimentos na área da Educação Ambiental, muitos professores elaboram atividades que proporcionam a aprendizagem através da prática. E, desta forma, eles vão construindo conhecimentos empiricamente, através dos seus próprios métodos de ensino e do contato com outros professores.

Algo essencial no combate à degradação do meio ambiente é a mudança nos padrões de produção, através de uma incessante busca da Produção mais Limpa. Para isto, é indispensável também a responsabilidade continuada do produtor. Da mesma forma, é ainda imprescindível a definição de responsabilidades para os produtores, consumidores, fornecedores, revendedores, entre outros.

A Produção mais Limpa é um conceito criado pelo Programa das Nações Unidas para o Meio Ambiente (PNUMA). Tal conceito prioriza a prevenção à poluição, a conservação de recursos naturais e a ecoeficiência. Esta luta por uma Produção mais Limpa evidencia o valor imensurável que todos devem dar ao meio ambiente e a tudo que o torna mais livre de agressões. 
Id on Line Revista Multidisciplinar e de Psicologia

Id on Line Multidisciplinary and Psycology Journal

Para que atitudes como esta sejam postas em prática o quanto antes, é necessária uma mudança na maneira de pensar. Para que assim, automaticamente, as pessoas sempre optem, em qualquer situação, pelas práticas mais sustentáveis.

Porém, foram as atitudes irresponsáveis e inconsequentes dos seres humanos que os fizeram chegar nessa atual crise ambiental. O que percebe-se, com isso, é que apelar apenas para a questão moral não é suficiente para se promover mudanças reais nas atitudes humanas. É preciso mais do que isso, para que se consiga o almejado passo na busca da sustentabilidade. De acordo com o exposto acima, pode-se declarar:

\begin{abstract}
A ação (e omissão) humana está na origem da atual crise ecológica. Dito de outro modo, são justamente as práticas inconsequentes e irresponsáveis dos seres humanos, nas mais diversas áreas de atuação, tanto privadas quanto públicas, que nos conduziram ao atual estado de risco existencial. Há, nesse sentido, para além da responsabilidade na esfera moral, também a necessidade de imposição de responsabilidades (deveres e obrigações) no campo jurídico, com o propósito de frear o ímpeto destrutivo que tem nos guiado nos últimos séculos, e de modo particularmente acelerado a partir da segunda metade do Século XX. (SARLET, 2014, p. 78)
\end{abstract}

A partir do que foi falado, é possível perceber que somente um movimento de conscientização não é capaz de mudar as pessoas. Porém, acrescentar-se a isso a imposição jurídica, possivelmente, não trará uma solução definitiva. Para que esta postura de respeito e proteção ao meio ambiente seja estabelecida na consciência das pessoas, é urgente que sejam inseridas nas escolas, não somente o estudo detalhado sobre o assunto, mas também a vivência de práticas diárias. É importante ressaltar que os efeitos positivos só serão verdadeiramente percebidos no dia a dia dos alunos, quando as atitudes de todos os professores e funcionários forem revistas. É fundamental que o ambiente escolar mostre, através do exemplo constante, somado ao estudo teórico e prático, a melhor maneira de agir nas diversas situações possíveis.

Porém, para que sejam disseminadas atitudes ecologicamente corretas nas escolas, não se faz necessária a inclusão de uma nova disciplina sobre educação ambiental. Pois, já existe um grande número de disciplinas escolares. E esta inserção, provavelmente, não traria mudanças reais na vida do aluno. Já que tal disciplina seria vista de maneira corrida, até por causa da falta de tempo.

O que deve ser feito com urgência é uma reformulação de todo o currículo escolar. Tudo isto com o objetivo de relacionar a problemática ambiental com todas as disciplinas existentes. Desta forma, os alunos estarão interiorizando, em todas as áreas, maneiras ecologicamente 
Id on Line Revista Multidisciplinar e de Psicologia

Id on Line Multidisciplinary and Psycology Journal

adequadas de pensar e agir. E assim, todos acabarão por adaptar-se facilmente às maneiras sustentáveis de vida.

\section{Considerações Finais}

Espera-se que este trabalho contribua para a premente mudança de postura da sociedade com relação ao meio ambiente, ajudando a reafirmar a necessidade de uma mudança de consciência social, reforçadora de uma mudança de atitude, enquanto ainda há tempo. Pois, depois de tantas leituras e discussões, fica claro que a única saída para a raça humana é agir sempre de forma ecologicamente correta.

O que todos devem ter em mente, diante da educação ambiental, é que para que os bons resultados sejam realmente atingidos, é imprescindível que todas as pessoas se movimentem, façam a sua parte. A mudança tem que acontecer de todos os lados, porque a degradação ambiental é alarmante!

É preciso entender que a educação ambiental não é apenas uma opção de vida. A natureza pede socorro! E se não forem tomadas as atitudes necessárias com seriedade e constância, as gerações futuras estarão seriamente ameaçadas. A principal meta de todos os cidadãos deve ser sempre a preservação da vida.

\section{Referências}

CARVALHO, Isabel Cristina de Moura. Educação ambiental: a formação do sujeito ecológico. 6. ed. São Paulo: Cortez, 2012.

DIAS, Genebaldo Freire. Educação ambiental: princípios e práticas. 9. ed. São Paulo: Gaia, 2004.

LEME, Taciana Neto. Conhecimentos práticos dos professores e sua formação continuada: um caminho para a educação ambiental na escola. In GUIMARÃES, Mauro (org.). Caminhos da educação ambiental: da forma à ação. 5. ed. Campinas, SP: Papirus, 2012.

MAZZINI, Ana Luiza Dolabela de Amorim. Nosso lixo de cada dia: desafios \& oportunidades. Belo Horizonte: Ed. do autor, 2008. 
SARLET, Ingo Wolfgang; FENSTERSEIFER, Tiago. Princípios do direito ambiental. São Paulo: Saraiva, 2014.

Como citar este artigo (Formato ABNT):

SAMPAIO, C.M.T. Educação Ambiental: a mudança que faz a diferença. Id on Line Revista Multidisciplinar e de Psicologia, Janeiro de 2017, vol.10, n.33, Supl 2. p. 74-86. ISSN: 1981-1179.

Recebido: 05/01/2017

Aceito: 09/01/2017 